\title{
Bio-inspired Design to Support Reduced Energy Consumption Via the 'Light Weighting' of Machine System Elements
}

\author{
Bukner Sven, Dialami Farid, Ding Lian, and Matthews Jason
}

\begin{abstract}
A potential technique to reduce the energy required to actuate moving parts in a machine is to reduce their mass. This paper presents initial research attempting to answer this question for robotic arm application using a biologically inspired approach. Investigation identified some potential biological solutions for tubular structures. From analysis of the properties of these biological models, the physical principles were deduced and abstracted into computer-aided design models for testing using finite element analysis. Three of the best performing design solutions were manufactured and physically tested. Findings showed that the biomimetic structures reached at least the same efficiency of conventional tubular structures regarding the ratio of maximum load and weight.
\end{abstract}

Index Terms-Biomimetics, lightweight design, bio-inspired structures, reduced energy consumption.

\section{INTRODUCTION}

Light-weighting of load bearings structures has seen an increased application in industry across many sectors [1]. An explanation for this trend is the economic significance of reducing the consumption of raw materials and energy used to construct and use manufacturing systems [2]. Today, the efficient use of resources needs to be taken into account in construction and manufacturing processes because of increasing costs. Processing and packaging systems are generally constructed of a series of generic parts to conduct a specific function [3]. Many of these parts are in motion as the machine carries out its design task. Whether this motion is actuated by mechanical or electrical sources. The lighter the part the less energy that is required to induce the motion. In solving a range of design problems such as that of this paper, scientists and engineers are forced to find new ways in the search for innovations [1]. One way to find a high amount of innovations is to observe how nature has solved problems, trying to try mimic solutions that it has presented. Therefore the research question becomes: is it possible to reformulate nature structures or strategies and create new high efficient economic technical structures? The highly efficient natural structures are optimized over millions of years and these so called 'patents' of the nature just need to be discovered and

Manuscript received June 23, 2014; revised August 30, 2014.

S. Burkner, J. Matthews, L. Ding are with University of South Wales. Pontypridd, Wales, United Kingdom, CF37 1DL, United Kingdom (e-mail: 12018406@students.southwales.ac.uk, jason.matthews@southwales.ac.uk, lding@southwales.ac.uk).

F. Dialami is with University of the West of England Coldharbour Lane, Bristol BS16 1QY United Kingdom (e-mail: farid.dialami@UWE.ac.uk). analysed. The selected case study for this application is load bearing robot arm structures. The elements between joints are generally tubular in nature to permit services and wiring to be internally channeled within the structure. The work presented in this paper has investigated suitable biological examples for the design of bio-inspired lightweight tubular structures for such load bearing applications. Natural structures have the desired properties which engineers are looking for, systems with a minimum of material and energy but in the same time maximal stability [4]. This is only possible by a judicious combination of mostly highly hierarchical material and perfect designed internal structures [5]. This combination is complex and it is useful to split them and investigate one of these elements. The chosen element for this paper is explicit the structure, that means the properties of materials of investigated biological examples are not considered.

\section{BACKGROUND}

\section{A. Biomimetics Overview}

Shu et al. [6] detailed the frequently used terminologies within the publications in the field of biomimetics where 'biomimesis, biomimicry, biognosis, bioinspiration, biomimetic design, bioanalogous design, biologically inspired design' are all considered synonymous. In order to prevent confusion, biomimicry and biomimetics will be used interchangeable throughout the paper. Biomimetic is a relative new term for a scientific discipline concerned with the transfer of biological findings into technology in several steps of abstraction and modification [7]. The scientific community has mainly concentrated on the investigations to find new materials. The main reason for this is that material has the greatest influence regarding strength, weight and thus more interest. However, biological structures have also their advantages in view of their mechanical properties. This paper investigates the question if biological inspired tubular structures have better properties under load than a conventional tube. A current problem is that biological knowledge from a purely technical perspective is limited or difficult to assess [7]. This work is based on many biological and technical sources to combine these two elements. However, all decisions, interpretations and explanations of results have an engineering background supported by biological sources. The connection of these two areas generates the combination of the words "biology", "mimesis"(imitation) and "technics": biomimetic [1].

\section{B. List of Used Biological Structures}

This subsection gives an overview of the some biological examples with accompanying explanations. Today, this 
science has the situation of no common knowledge pool. The research costs in this science are high thus it is an economic decision for companies and institutes to hold back their research results for further own projects [4]. This does not mean that there is no collaboration between institutions regarding the exchange of know-how and knowledge. However, it needs more time until this science is completely available for companies with manageable costs. This paper shows the possibility to develop new biomimetic structures on a low cost level.

With this in mind, there are many other examples from the history of bionics after Da Vinci, human inventions were certainly from the beginning inspired by the nature. These primitive inventions are called "Low-Tech-Bionic"[1]. Today, scientists and engineers are trying to absorb quantitative biological structures and principles to transfer them to technical application. This approach is called "HighTech Bionic" [1] and has an increasing importance for economy. Examples for non-bio-inspired technical analogy developments in the history have been the zipper, a zip-system imitates the insect pygmy backswimmer while he is fixing his wings together [8]. Lineman's pliers, ant lions are a group of insects equipped with mouthparts [8]. Some other well-known examples are the self-cleaning ability of many plants, Velcro and sharkskin bathing costumes.

\section{Methodology}

The whole biomimetic process has to follow a "Top-Down" approach. Currently, developers are often acting in company/ financial specific thinking strategies when searching for new concepts and solutions. Sometimes it is crucial to tread new paths on the way for new innovations. Biomimetics is an analogy-based method and requires a new kind of methodology regarding construction processes. Currently, no one general approach has been developed for biomimetics. One reason could be the relatively short history of this particular science. Prototypes were developed according to the Top-Down process which is also called "Analogy Bionic" [7]. Analogy-bionic means the specific search in biology for solutions of technical problems [4]. A representation of such an approach can be seen in Fig. 1.

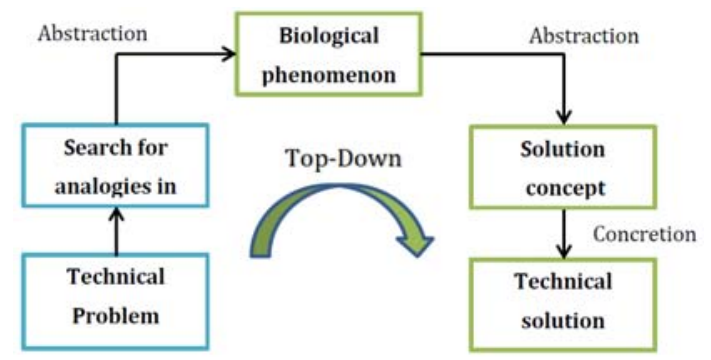

Fig. 1. Top-down process is problem-oriented approach.

In the instance of this research a formal methodology was required, the generic Top Down method (see Fig. 1a) is further abstracted into the followed six steps.

\section{A. Step 1: Task Clarification}

As with any design process the initial step is a description of task to be performed and the formulation of a list of requirements that are tailored to meet the needs of the customer(s).

\section{B. Step 2: Abstract Functional Characteristics}

Before suitable structures can be found it is necessary to establish abstract functional characteristics. As an example, for this research, the main focus is on structures with the property of combining lightweight and stability.

\section{Step 3: Analogical Form}

The most efficient way of finding suitable biological structures with similar characteristics is to look for different sources. Most of the structures were found during the process of looking for information for the literature review. In particular, the communication with institutes and other institutions gives an overview of current research projects and publications. These projects and publications investigate structures of highest scientific interest. Furthermore, the potential of these structures is proved and based on the knowledge of biologists.

\section{Step 4: Functional Analysis of Templates}

The Functional analysis of templates is important regarding the ability of transferring the structure into a tube-profile. This step has also the opportunity to lead back to step two in cases of a negative result. In this case, it is helpful to choose a higher degree of abstraction. That means a greater simplification to the original. It is important that biomimetic does not mean a one to one transmission because this is not possible. Good solutions are a result of a well-chosen degree of abstraction. The "Law of similarity" helps to check a structure in most cases. As described previously, this paper looks explicit for structures and not for the material properties. For example, the bamboo is one of the best structures regarding lightweight, strengths and shape. Nevertheless, a bamboo is a highly organized multi-scale structured composite. But without this material property is a bamboo only a tube without a special structure - although a normal tube is also an efficient shape regarding the area moment and the stiffeners are not considered. That means most of the known structures fails this fourth step because they get their strength from the material. A Plant stem is a better example because the material is only one part of its efficient double ring structure. If a biological model suitable, it will be transferred in a Computer Aided Design (CAD) model for Finite Element Analysis (FEA).

\section{E. Step 5: Functional Analysis of Templates}

All structures are already chosen and can now be transferred into CAD models, an example of this is shown in Fig. 2. Parts a and b, show an abstraction of a bird bone. The final structure is a result of multiple tests during changing details until the desired strengths are reached. The FE Analysis can identify areas with high and low stresses. The material can be removed in areas with a low value of stress and added in areas of high stresses. An example of this for the abstracted bird bone is shown in part c of the Fig. 2 .

\section{F. Step 6: Comparative Evaluation of Solution Variants}

Before the data can be analyzed the implementation of an evaluation system is required. The pairwise comparison is a 
suitable tool to establish the value of the weighting factors. The example for this paper attaches importance to the following five properties:

- Weight
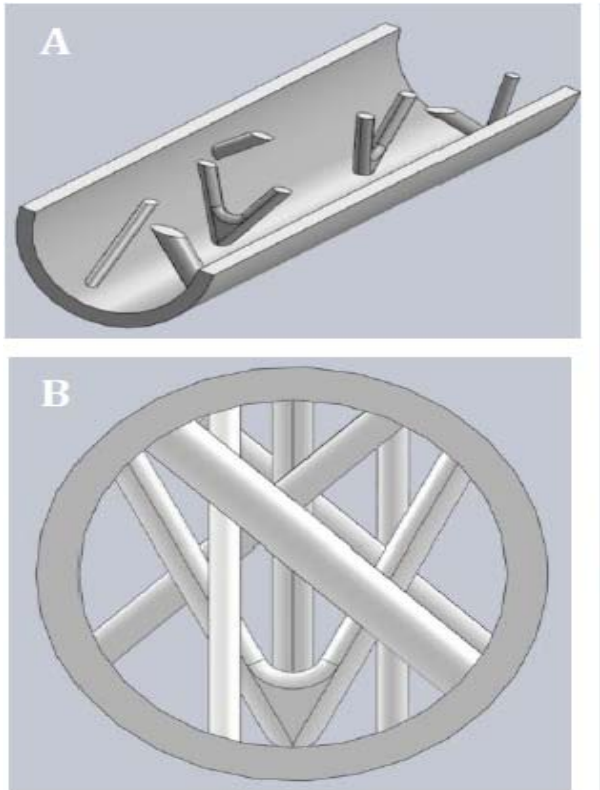

Fig. 2. A cross section of the bird bone inspired CAD-model $b$ front view of the CAD model c CAD-model after bending test. The green arrows are the fixture and the purple arrow rows an applied bending force.

1.)

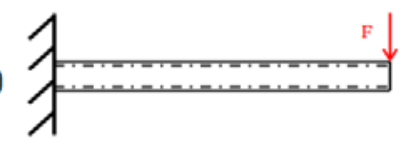

2.)

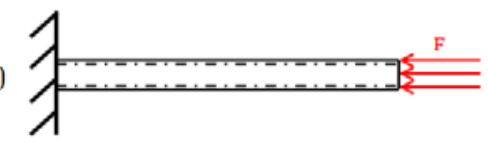

3.)

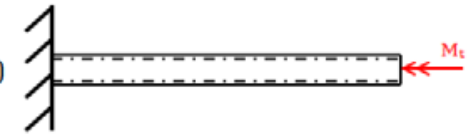

Fig. 3. Principle drawing of all stress tests used for the FE-analysis of the models.

Every property gets a specific weighting factor. The evaluation of the test results will be done by an evaluation matrix with these five established weighting factors. The evaluation points are out of the VDI 2225 [9] evaluation system. This paper uses additionally own created Lightweight numbers (LWN) to determine the efficiency of each model. This is a specific evaluation of models for this paper in a simple way and should not be confused with the Lightweight numbers for materials [10]. The LW-number is a result of load divided by model-weight with the significance: the higher the LW-number the higher is the efficiency.

$$
\mathrm{LWN}=\frac{\text { maxload }}{\text { weight }}
$$

There are three kinds of tests which will deliver three different LW-numbers:

- LWN-B - Bending

- LWN-C - Compression

- LWN-D - Torsion

These are represented in Fig. 3 in the context of the tubular structures.

These numbers are helpful to show the strengths and
- Maximum tolerable bending force

- Maximum tolerable compression force

- Maximum tolerable torsion

- Area moment of inertia 


\begin{tabular}{|c|c|c|c|c|c|c|}
\hline & & Weight & $\begin{array}{c}\text { Max } \\
\text { Bending } \\
\text { force }\end{array}$ & $\begin{array}{c}\text { Max. } \\
\text { Moment of } \\
\text { Rotation }\end{array}$ & $\begin{array}{c}\text { Max. } \\
\text { Compression } \\
\text { Force }\end{array}$ & $\begin{array}{c}\text { Area } \\
\text { Moment of } \\
\text { Inertia }\end{array}$ \\
\hline No. & Criteria & 1 & 2 & 3 & 4 & 5 \\
\hline 1 & Weight & & 1 & 1 & 1 & 1 \\
\hline 2 & Max. Bending Force & 3 & & 2 & 1 & 2 \\
\hline 3 & $\begin{array}{l}\text { Max. Moment of } \\
\text { Rotation }\end{array}$ & 3 & 2 & & 1 & 1 \\
\hline 4 & $\begin{array}{l}\text { Max. Compression } \\
\text { Force }\end{array}$ & 3 & 3 & 3 & & 3 \\
\hline 5 & $\begin{array}{l}\text { Area Moment of } \\
\text { Inertia }\end{array}$ & 3 & 2 & 3 & 1 & \\
\hline & Point & 12 & 8 & 9 & 4 & 7 \\
\hline & Position & 1 & 3 & 2 & 5 & 4 \\
\hline & $\begin{array}{l}\text { Weighting } \\
\text { Factors }\end{array}$ & 0.3 & 0.2 & 0.225 & 0.1 & 0.175 \\
\hline
\end{tabular}

Snail Shell - Nautilus: The Nautilus snail is not one of the most relevant species in biomimetic. Nevertheless, is the construction of the snail shell unusual because of the spiral pattern? These internal truss elements are supporting the shell against external pressure [11]. The abstraction and testing of this structure can possibly demonstrate a significance of this structure for bionics. There are several questions regarding this structure. Can this spiral pattern carry a torsion force and in which torsion direction

Fold-structures: The nature uses fold structures also as stiffening elements to safe weight and thus material [12]. There are many biological systems which use this principle additionally for saving space. The natural models for this paper are the wing of a firefly and the fan palm. In particular, the wing of a firefly is of enormous interesting. The wing has a fold structure and between each fold is a membrane. The folds are parallel to a good approximation to the wing axis, so just the longitudinal direction is stabilized against flexing. This combination ensures an extremely lightweight with the unreached flight qualities [13]. The Fan palm has a V-shaped fold structure and the so called leaf blade provides the necessary stiffness.

Plant Stem (Haulm): The haulm structure of so called "True grasses" belongs to the structural and mechanical most impressive biological constructions the nature have. These plants combine lean haulm with very good mechanical properties and this although a secondary thickness growing is not possible. The diameter of haulms is nearly fixed from the beginning of the growth and is characterized by nodes and internodes. This structure is very similar to a tube in view of thickness and constant diameter over the length. This is also a structure which needs only a relatively low degree of abstraction for the transfer into a tube profile. Another long thin and stable structure is a hedgehog thorn. Especially the internal structure is of interest.

Honey Combs: Honey combs have the properties of high stability and simultaneously low weight [12]. Loads are distributed over the walls of the entire honeycomb thus do not act punctual. The hexagonal shape gives the construction stability and safes resources. This shape is an excellent example for utilization of material [12].

Hedgehog Thorn: The hedgehog thorn has fibrillated built walls and the insides are axial beam structures [4]. The hedgehog thorn also uses transverse plates for a shock absorbing function. All these elements together ensure high stability.

\section{Step 4}

The selected biological models have already known strengths and the engineer has only to ask the right questions on the search for suitable structures.

\section{Step 5}

The virtual models were constructed in the modelling environments, these are shown in Fig. 4. For the analysis of the models, the SolidWorks CAD software combined with "ANSYS" as a Finite Element (FE)-simulation tool was employed.

This research used fixed equal boundary conditions for the simulations of the parts. The use of equal conditions is necessary because this ensures comparable results. Furthermore, all simulations are linear-static and the tensile strength of material will never be exceeded. The FE-Analysis is a mathematical tool and consists of many idealization assumptions. Every idealization means an increase in difference between the real model and the FEA-model [13]. These idealizations have to be taken into account while evaluating the results after simulation. For FEA analysis the following assumptions are valid:

- Approximation of the physical parameter inter alia of mass density and stiffness [13]

- Approximation of the geometry inter alia of the surface roughness is neglected [8].

- All material's characteristic values are not deviate, that means the material has no faults as for example blowholes Neglecting of the molecular structure, the material is isotropic and homogenous

- The FEA simulation is only based on a nearly infinite slow simulation in theory so that there is no resulting heat or friction [8]. Additionally, no relax of the plastic material

- Simplification of the geometry, e.g. fillets are approximated by straight sections

- The FEA builds a finite number of elements with a 
noncomplex shape [13]

- No internal material stresses exist [13]

- The material is subjected to the Hook's Law

- Neglecting of acceleration and velocity effects while simulation. A displacement in a particular time results according to physics in velocity. But this velocity is very small and therefore not relevant linear displacements.

All these assumptions are important to consider. Especially the simulation of complicated models can be different to the real model because of these simplifications. This work uses a static 3D-analysis because of non-constant shapes and diameters.

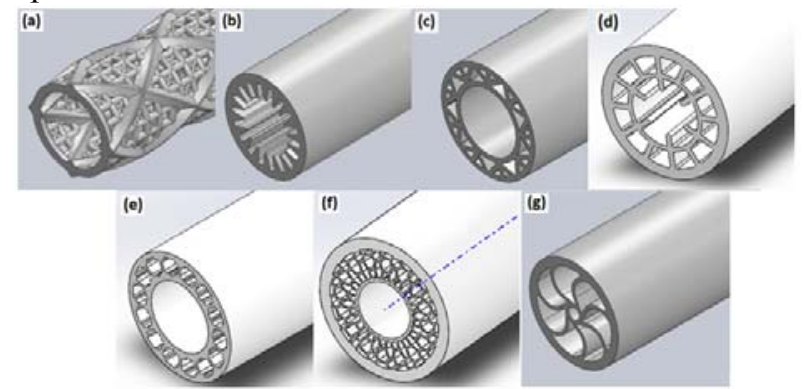

Fig. 4. a. Glassy sponge; b. Hedgehog quill; c. folded; d. Algae; e. haulm; f. honey combe; g. snail shell.

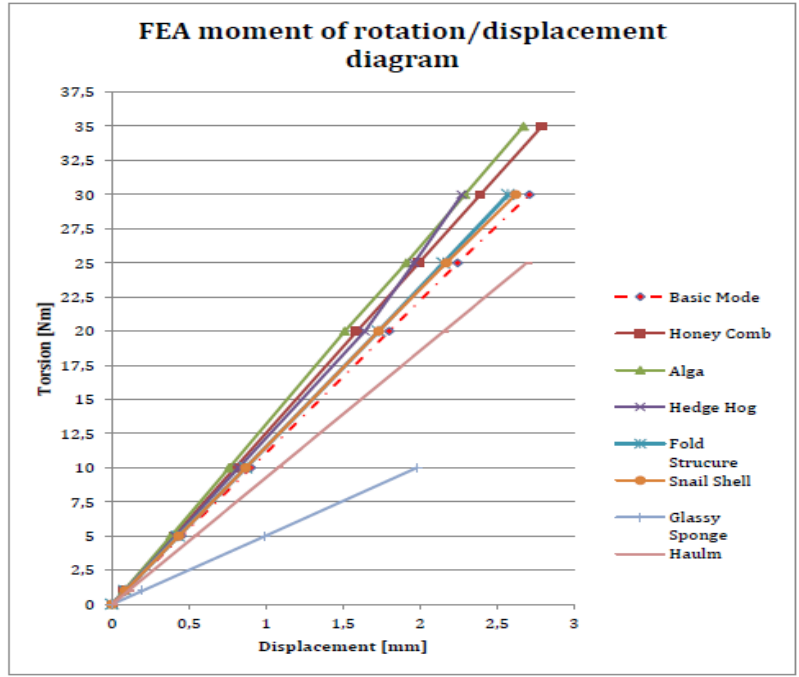

Fig. 5. FEA rotation/ displacement graph.

\section{E. Step 6}

The important factors in this application are that of, compression, torsion and bending are important requirements for the used tubular structure. The compression of the arm is not where to focus on and therefore it is not of high importance. It follows the implementation of specific weighting factors for the determination of a suitable tube structure. Fig. 5-Fig. 7 presents the results of the FE Analysis.

Lightweight numbers are a simple but useful way to establish the lightweight efficiency of a model and their strengths and weaknesses. Table I illustrates the pairwise comparison consisting of five criteria's. The evaluation points are out of the VDI 2225 [9] evaluation system in which three is the highest value and one the lowest. The resulting weighting factors are a result of the percentage achieved points. The weight has the highest importance and the maximum compression force the lowest significance.
Evaluation, 3 being most important and 1 being least. The resulting amount of points after the pairwise comparison delivers the weighting factors. The "weight" reached a factor of 0.3 and the maximum "compression force" a factor of 0.1 .

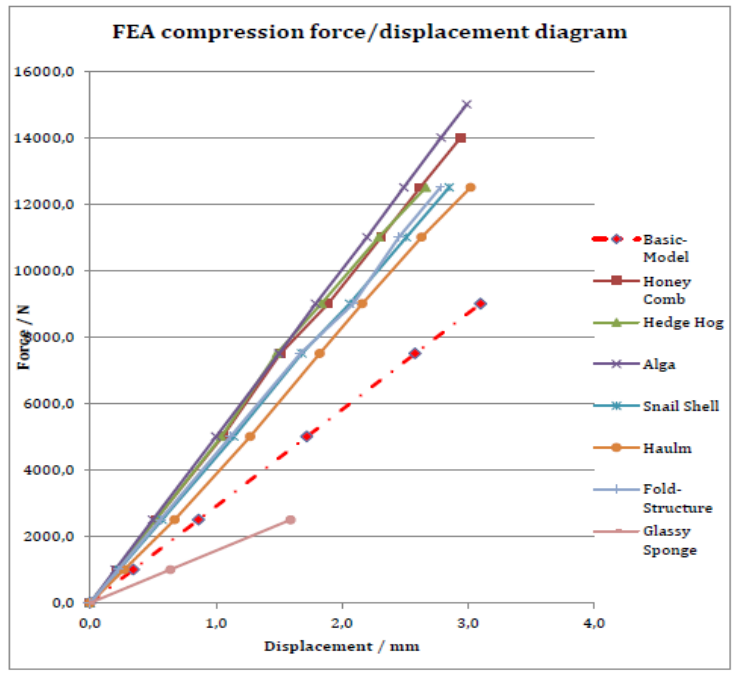

Fig. 6. Compression/ displacement graph.

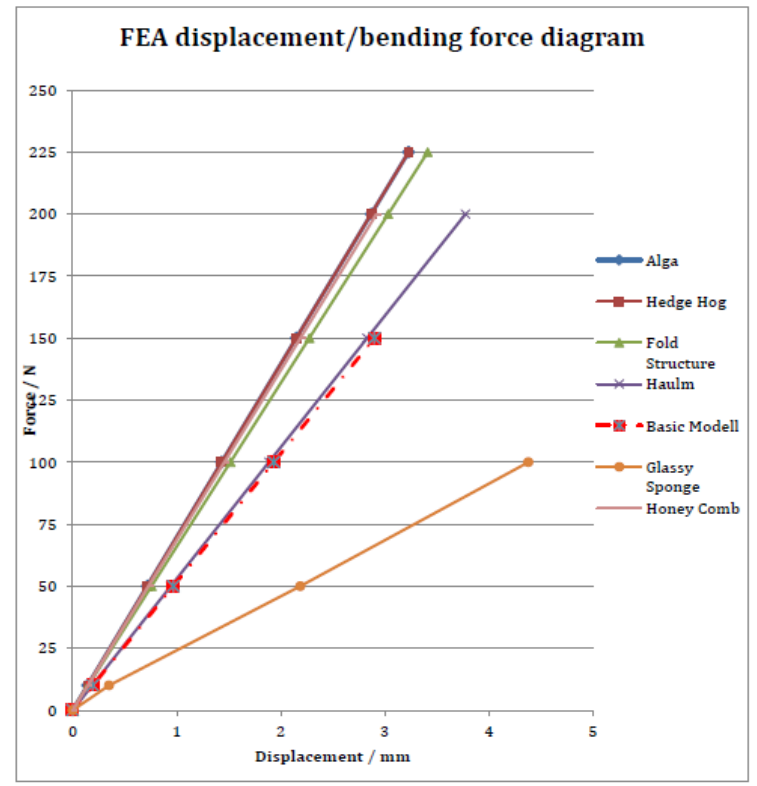

Fig. 7. Bending force/ displacement.

TABLE II (I): MODEL SELECTION

\begin{tabular}{|c|c|c|c|c|c|c|}
\hline \multicolumn{7}{|c|}{ Target: Search for suitable models } \\
\hline \multicolumn{3}{|c|}{ Concept Variants } & \multicolumn{2}{|c|}{ Alga } & \multicolumn{2}{|c|}{ Honey Comb } \\
\hline No. & Evaluate criteria & g & EP & EP xg & EP & EP xg \\
\hline 1 & Weight & 0.3 & 1 & 0.3 & 1 & 0.3 \\
\hline 2 & Max. Bending Force & 0.2 & 4 & 0.8 & 3 & 0.6 \\
\hline 3 & $\begin{array}{l}\text { Max. Moment of } \\
\text { Rotation }\end{array}$ & 0.225 & 4 & 0.9 & 4 & 0.9 \\
\hline 4 & $\begin{array}{l}\text { Max. Compression } \\
\text { Force } \\
\end{array}$ & 0.1 & 4 & 0.4 & 3 & 0.3 \\
\hline \multirow[t]{2}{*}{5} & Area Moment of Inertia & 0.175 & 4 & 0.7 & 3 & 0.525 \\
\hline & $\Sigma$ & 1 & 17 & 3.1 & 14 & 2.625 \\
\hline \multicolumn{3}{|c|}{ Position } & \multicolumn{2}{|c|}{1} & \multicolumn{2}{|c|}{6} \\
\hline
\end{tabular}

The evaluation matrix was necessary to establish three models with the best properties. The selected models will be explicit improved for the following tests respectively production (Table II). 
TABLE II (II): MODEL SELECTION

\begin{tabular}{|c|c|c|c|c|c|c|}
\hline \multicolumn{7}{|c|}{ Target: Search for suitable models } \\
\hline \multicolumn{3}{|c|}{ Concept Variants } & \multicolumn{2}{|c|}{ Hedge Hog } & \multicolumn{2}{|c|}{ Snail Shell } \\
\hline No. & Evaluate criteria & g & EP & EP xg & EP & EP xg \\
\hline 1 & Weight & 0.3 & 1 & 0.3 & 2 & 0.6 \\
\hline 2 & Max. Bending Force & 0.2 & 4 & 0.8 & 3 & 0.6 \\
\hline 3 & $\begin{array}{l}\text { Max. Moment of } \\
\text { Rotation }\end{array}$ & 0.225 & 3 & 0.675 & 3 & 0.675 \\
\hline 4 & Max. Compression Force & 0.1 & 3 & 0.3 & 3 & 0.3 \\
\hline \multirow[t]{2}{*}{5} & Area Moment of Inertia & 0.175 & 4 & 0.7 & 3 & 0.525 \\
\hline & $\Sigma$ & 1 & 15 & 2.775 & 14 & 2.7 \\
\hline \multicolumn{3}{|c|}{ Position } & \multicolumn{2}{|c|}{4} & \multicolumn{2}{|c|}{5} \\
\hline
\end{tabular}

TABLE II (III): MODEL SELECTION

\begin{tabular}{|c|c|c|c|c|c|c|c|c|}
\hline \multicolumn{9}{|c|}{ Target: Search for suitable models } \\
\hline \multicolumn{3}{|c|}{ Concept Variants } & \multicolumn{2}{|c|}{$\begin{array}{c}\text { Fold } \\
\text { Structure }\end{array}$} & \multicolumn{2}{|c|}{$\begin{array}{l}\text { Glassy } \\
\text { Sponge }\end{array}$} & \multicolumn{2}{|c|}{ Haulm } \\
\hline No. & $\begin{array}{c}\text { Evaluate } \\
\text { criteria }\end{array}$ & $\mathrm{g}$ & EP & EP xg & EP & $\mathrm{EP} \times g$ & EP & $\begin{array}{l}\text { EP } \\
\mathrm{xg} \\
\end{array}$ \\
\hline 1 & Weight & 0.3 & 2 & 0.6 & 4 & 1.2 & 3 & 0.9 \\
\hline 2 & $\begin{array}{c}\text { Max. } \\
\text { Bending } \\
\text { Force }\end{array}$ & 0.2 & 4 & 0.8 & 1 & 0.2 & 3 & 0.6 \\
\hline 3 & $\begin{array}{c}\text { Max. } \\
\text { Moment of } \\
\text { Rotation } \\
\end{array}$ & $\begin{array}{l}0.2 \\
25 \\
\end{array}$ & 3 & 0.675 & 2 & 0.45 & 3 & $\begin{array}{c}0.67 \\
5 \\
\end{array}$ \\
\hline 4 & $\begin{array}{c}\text { Max. } \\
\text { Compressi } \\
\text { on Force }\end{array}$ & 0.1 & 3 & 0.3 & 1 & 0.1 & 3 & 0.3 \\
\hline 5 & $\begin{array}{c}\text { Area } \\
\text { Moment of } \\
\text { Inertia } \\
\end{array}$ & $\begin{array}{l}0.1 \\
75 \\
\end{array}$ & 3 & 0.525 & 1 & 0.175 & 2 & 0.35 \\
\hline & $\Sigma$ & 1 & 15 & 2.9 & 9 & 2.125 & 14 & $\begin{array}{c}2.82 \\
5 \\
\end{array}$ \\
\hline \multicolumn{3}{|c|}{ Position } & \multicolumn{2}{|c|}{2} & \multicolumn{2}{|c|}{7} & \multicolumn{2}{|c|}{3} \\
\hline
\end{tabular}

\section{INVESTIGATION: PART II}

With the appropriate biomimetic designs selected, the next stage is to manufacture their abstractions. Due to the complex nature of some of the designs, the most suitable and repeatable technique for their manufacture is that of Additive Layer Manufacture (ALM) or 3D printing. The ALM system was set up to consider the process limitations as identified by Blomer et al. [14] in relation to the product. It is assumed that this process is able to build comparable structures with enough strength for practical testing's. To get an average result of every test it is meaningful to build five parts of each model for each kind of test. The three structures selected were Algae, Folded and Glassy sponge. Although the glassy sponge presented limited capability in the FEA testing, it was decided that because of current published works, it theoretically offers potential for this application. The results were also compared against a plain tube structure with a $3 \mathrm{~mm}$ wall produced on the same process. Manufactured parts can be seen in Fig. 8.

The practical tests show what kind of strengths and weaknesses theses biomimetic tubes and plain tube structure profiles have under real load conditions. The compression tests were conducted on an Instron 8502 servo-hydraulic fatigue testing system (cf. Fig. 9a) and the bending tests were produced on a Zwick Z010 materials testing system (cf. Fig. $9 b)$. The torsion tests had not been completed at the time of publication of this article as the existing clamping devices damaged the structures prior to testing. The practical stress tests have the same scheme like the simulation. The practical's consisted of a compression- and a two point bending tests.

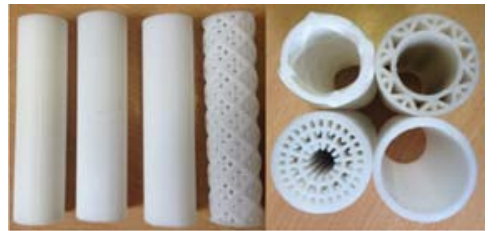

Fig. 8. Sample parts manufactured

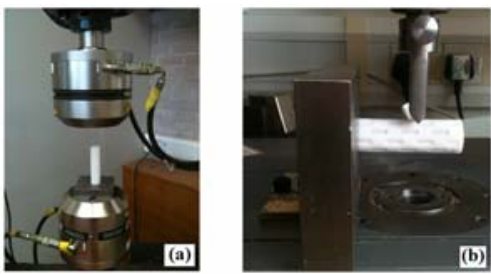

Fig. 9. Practical test setups.

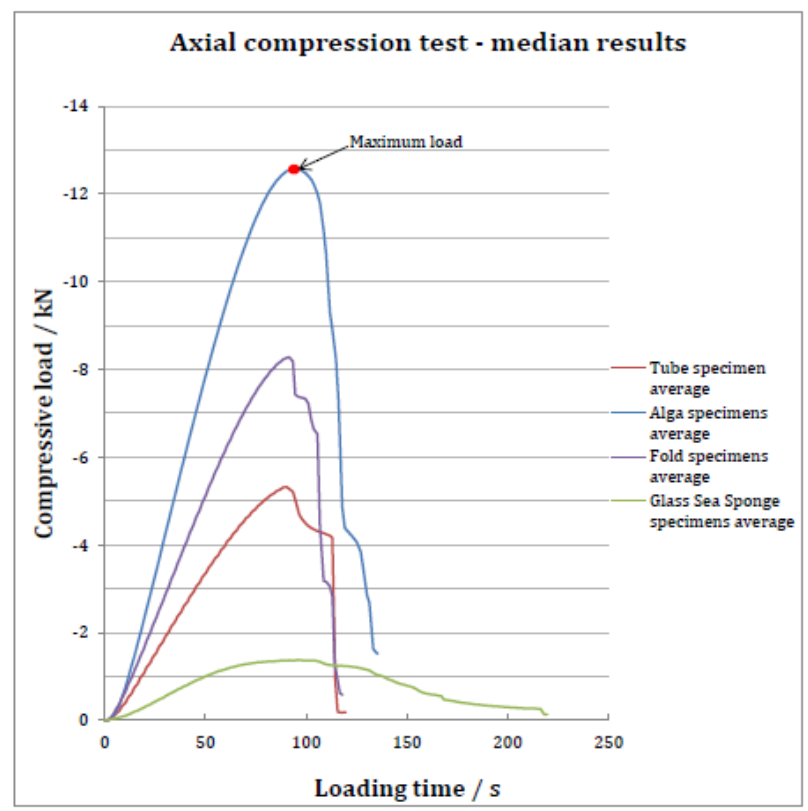

Fig. 10. Compression tests.

The chosen load velocity of $2 \mathrm{~mm} / \mathrm{min}$ is suitable to carry out the compression tests. It is important that the material has not enough time to relax because this increases the elongation. Fig. 10 illustrates a load/loading time diagram with the averaged curves of all tested specimens. The load increases until the maximum yield stress is reached. After this point the structures are plastically deformed and they are no longer able to carry the load. That means the area after the yields stress is not relevant because of the damaged specimen structure. All structures reached the maximum load after $\approx 90$ seconds $(3 \mathrm{~mm})$ with the exception of the Glass Sea Sponge. The Sponge structure has no high resistance and reduces stress like an accordion because of insufficient manufactured cross sections. All models have about $25 \%$ less strength compared with the FEA results. A reason for this is that the FEA tests have optimal conditions and an infinitive small load velocity. However, the difference of the maximum stress values between the structures is approximately equal to 
the simulation and confirms the trend.

The resulting LW-numbers are showing how close the results of the Alga-, Fold- and Tubular structure are. The LW-numbers (see Table III) show that the biomimetic structures are not more effective than the comparative tubular structure. This is a consequence of the amount of previously mentioned restrictions.

TABLE III: Average TeSt VALUES OF THE SPECIMENS - COMPRESSION TEST

\begin{tabular}{|l|c|c|c|c|c|}
\hline & Units & $\begin{array}{c}\text { Tubular } \\
\text { S }\end{array}$ & Alga & Fold & Sponge \\
\hline Max load & $\mathrm{N}$ & -5.51 & -12.58 & -9.83 & -1.39 \\
\hline LWN-C & $\mathbf{N} / \mathbf{g}$ & $\mathbf{3 7 8}$ & $\mathbf{3 8 3}$ & $\mathbf{3 7 9}$ & $\mathbf{1 3 3}$ \\
\hline Length & $\mathrm{mm}$ & 100.28 & 99.78 & 100.1 & 100.1 \\
\hline Diameter & $\mathrm{mm}$ & 25.03 & 24.7 & 24.89 & 25.01 \\
\hline Weight & $\mathrm{g}$ & 14.57 & 98.8 & 22.23 & 10.43 \\
\hline
\end{tabular}

TABLE IV: AVERAge TeSt VALUES OF THE SPECIMENS USED FOR THE TWO POINT BENDING TEST\#

\begin{tabular}{|l|c|c|c|c|c|}
\hline & Units & $\begin{array}{c}\text { Tubular } \\
\text { S }\end{array}$ & Alga & Fold & Sponge \\
\hline Max load & $\mathrm{N}$ & 386.5 & 892 & 627 & 173 \\
\hline LWN-B & $\mathbf{N} / \mathbf{g}$ & $\mathbf{2 6 . 7}$ & $\mathbf{2 6 . 2}$ & $\mathbf{2 6 . 1}$ & $\mathbf{1 6 . 4}$ \\
\hline Length & $\mathrm{mm}$ & 100.09 & 100.04 & 100.18 & 100.01 \\
\hline Diameter & $\mathrm{mm}$ & 25.05 & 24.98 & 24.9 & 25.01 \\
\hline Weight & $\mathrm{g}$ & 14.5 & 34 & 24 & 10.55 \\
\hline
\end{tabular}

The force-displacement curve is given in Fig. 11 it show the high displacements of the specimens until the tensile strength is reached. The high displacement/strain is a consequence of the low load velocity. The curves are almost linear in the elastic region before the ultimate tensile strength. Note how elastic this amorphous ABS thermoplastic is. The highest loads are reached at a displacement $>5 \mathrm{~mm}$. The intervals between the highest loads are almost equal to the compression test.

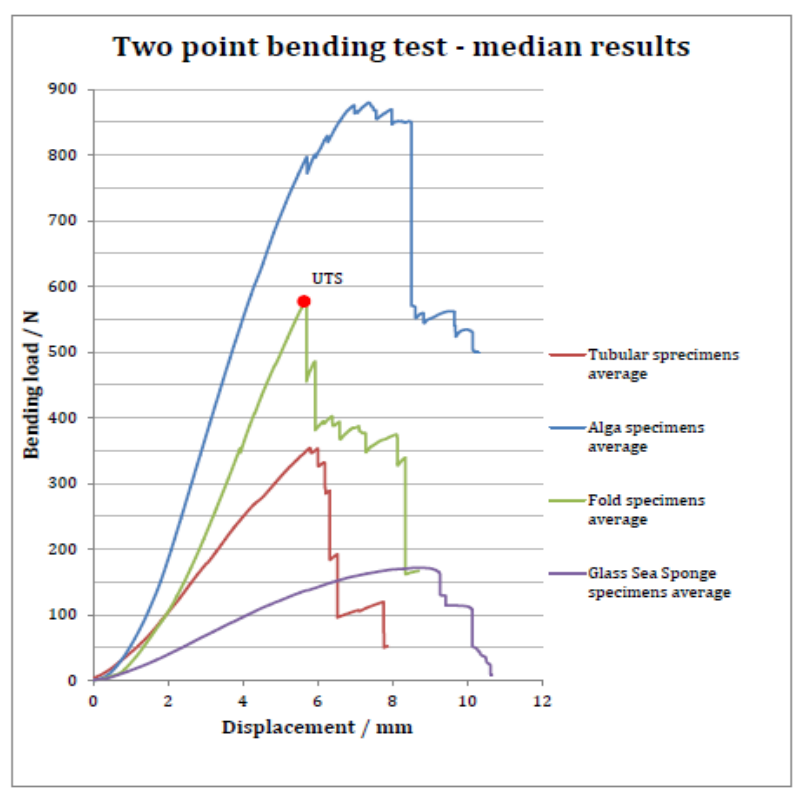

Fig. 11. Practical test results.

The resulting bending LW-numbers enable a better interpretation of the results (see Table IV). The LWN-B of the Tubular-, Alga- and Fold structure are again almost equal. This is a consequence of the amount of previously mentioned restrictions. Despite the limitations it was not expected that the LW-number are so close. All biomimetic structures have again no better outcomes than the comparative structure.

\section{DISCUSSION}

Finite element analysis (FEA) in combination with rapid prototyping is offering great opportunities to create knowledge about the behavior of biomimetic structures. The

use of FEA gave the opportunity to design and improve the CAD-models until the desired structures were reached. The only restriction in FEA was the simulation of models with internal disordered structures like inter alia struts. The FEA-software was not able to include these internal elements into the simulation. As a consequence, no internal disordered structure (e.g. Bird bone, Femur bone) could be taken into account. The evaluation matrix was a suitable tool to evaluate the simulation results. The three most appropriate chosen structures are the Alga, Fold and Plant Stem. These structures

reached the highest points for the purpose of a load bearing application. The Plant Stem is the best investigated structure regarding the lightweight numbers (ratio of maximum load and weight) of compression and bending. The Plant Stem structure carries theoretically $6.16 \% \mathrm{~N} / \mathrm{g}$ more bending force and $24.9 \% \mathrm{~N} / \mathrm{g}$ more compression loads than the comparative model. Furthermore, the resistance against torsion is equal to the normal tubular structure with a value of $1.36 \mathrm{~N} / \mathrm{g}$.

Potentially the most interesting structure of this paper was the Glass sea sponge. This Sponge is highly complex and the structural functions are difficult to understand but it has a lot of potential for innovations regarding lightweight structures. For that reason, the Glass sea sponge was selected instead of the already known Plant Stem for practical tests. It must be mentioned out that the Lightweight numbers were initially created for this paper for the purpose of a clear comparative overview of the strengths and weaknesses of all models and had no influence on the evaluation process. This is because the idea for these numbers came after the models had been selected. The informative value of the LW-numbers turned out later. An earlier use of these LWN would have affected the assessment process. However, the LWN can be used for further lightweight projects in the future.

It should be noted that there was a consistent variation in the virtually modelled specimens in comparison to the results obtained in the physical testing. One explanation is that the FEA tests were carried out in the elastic area of a stress-stain diagram. The maximum load is located at the tensile strength. FEA never reached the tensile strength because of a static velocity which has an important influence on the strength. Other result differences were put down to the limitation of the ALM process. Although previous researchers have identified that the glassy sponge is a good model to follow, it shows poor results in every testing in comparison to other structures. Two reasons were responsible for this. Firstly, FEA was not able to include the whole structure into the simulations with the consequence of less strength. Secondly, the resolution of the manufacture process meant it was not able to build the important cross section areas. That means only the external spiral ridges were accurate manufactured as only on part of the whole structure. 


\section{CONCLUSION}

This paper presented early phase of an investigation to the application of bio-inspired inspired elements into the design of load bearing structures to be deployed in a robots arm. The initial hypothesis was that a reduction in the weight of that such machine parts would reduce the energy required to actuate them. To design lighter elements, a proposition was to investigate solution presented by nature. In the absence of a formal methodology this paper proposed an approach, whereby the abstraction and testing of bio-inspired structures could be rigorously conducted. A combination of computation and physical modelling was employed to produce and test abstracted designs from nature.

For assessment of the potential designs the paper proposes the 'lightweight number' (LWN) concept under bending, compression and torsional loads. The LWN is derived by dividing the respective maximum load on a structure by its weight. When considering the LWN principle the work has shown that such bio-inspired structures can at least achieve the same performance as that of the basic structure. This at least shows potential that with some refinement, bio-inspired structures can be used to produce lighter part, with less material, resulting in reduced energy consumption in their application and motion.

\section{FUTURE WORK}

The following recommendations are import to avoid mistakes in future biomimetic projects and can help to improve the quality of results:

- The completion of the torsional testing missing from this article, to confirm FEA modelling.

- Further optimization of computation models, to see if their fidelity can be increased.

- An investigation into the effects of the manufacturing process has on the results, trying different ALM processes.

- The next major stage is to investigate the relationship between the structure and the materials.

\section{REFERENCES}

[1] T. Speck and C. Neinhuis, Naturwissenschaftliche Rundschau, 2004, pp. 177-184.

[2] J. Matthews, C. Parr, O Araoye, and M. M. Manus, "Environmental auditing of a packaging system for redesign: a case study exploration," Journal of Clean Energy Technologies, vol. 2, no. 3, pp. 267-273, 2013.
[3] W. Nachtigall, Bionik - Grundlagen und Beispiele für Ingenieure und Naturwissenschaftler, Berlin: Springer Verlag, 2002.

[4] J. Matthews, L. L. Ding, J. Feldman, and G. Mullineux, "The maintenance and handling of constraints in machine design," in Proc. the ASME International Design Engineering Technical Conferences and Computers and Information in Engineering Conference New York: 2009, pp. 443-452.

[5] L. H. Shu, K. Ueda, I. I. Chiu, and H. Cheong, "Biologically inspired design," CIRP Annals - Manufacturing Technology, vol. 60, no. 2, pp 673-693, 2011.

[6] J. Weaver, J, Aizenberg, G, Fantner, D, Kisailus, A, Woesz, and P. Allen, "Hierarchicalassembly of the siliceous skeletal lattice of the hexactinellid sponge Euplectella aspergillum," Journal. of Structural. Biology, vol. 158, pp. 93-106, 2007.

[7] M. Milwich, T. Speck, T. Stegmaier, and H. Planck, "Biomimetics and Technical Textiles: Solving engineering problems with the help of nature's wisdom," American Journal. Of Botany, vol. 93, no. 10, pp. 1455-1465, 2006.

[8] F. Malik, Werner Testlabor Natur, Faszination Natur, München: Bionik Media GmbH, 2006.

[9] VDI 2225 Evaluation System, "Technisch-wirtchaftiliches Konstruieren, VDI-Vertag, Dusseldorf, 1977.

[10] B. Klein, Leichtbau-Konstruktion: Berechnung sgrundlagenund Gestaltung, Wiesbaden: Vieweg+Teubner Verlag, Auflage, 2011, pp. 33-35.

[11] C. Hamm, Das Leben Im Plankton, Faszination Bionik. München: Malik Management Zentrum St. Gallen, 2006.

[12] K. G. Blüchel, Faszination Bionik, München: Malik Management Zentrum St. Gallen, 2008

[13] C. Gebhard, FEM mit ANSYS und Workbench, Einführung in die lineare undnichtlineare Mechanik, München: Carl Hanser Verlag, 2011.

[14] J. Blömer, J. Gerken, H. Flötotto, A. Bernotat, R. Jaeger, and T. Rechtenwald, Bionic Manufacturing, Bundesministerium für Bildung und Forschung. 2012.

Farid Dialami is a senior lecturer in the Faculty of Computing, Engineering and Mathematical sciences at the University of the West of England, specializing in the subject of mechatronics. He is a member of the Bristol Institute of Robotics (BRL). His current research interests deal with the increased utilization of robotic systems to support manufacturing processes

Jason Matthews is the subject leader for mechanical engineering in the Faculty of Computing, Engineering and Science and a member of the Energy and Environment Research Institute at the University of South Wales. He received his $\mathrm{PhD}$ from the University of Bath. His current research interests deal with the creation of tools and methods to support the improved design and operation of, high speed production machinery and machine tool systems.

Lian Ding is a manufacturing lecturer in the Faculty of Computing, Engineering and Science at the University of South Wales. She received her BEng and MSc in mechanical engineering in China. Her research interests include product modelling, integration of $\mathrm{CAD} / \mathrm{CAM}$, feature-based techniques, Product Lifecycle Management, Artificial Intelligence: neural network, genetic algorithm and fuzzy logic.

Sven Burkner is a student of Hochschule Hanover, (University of Applied Science and Arts) Germany and is currently undertaking research into biomimetics in the Faculty of Computing, Engineering and Science at the University of South Wales. 